\title{
"Talking Standards, Minimal Application" Use of Reliable Personality Assessment Tools for the Mere Sake of Being Scientific
}

\author{
Aggarwal Sapna
}

\section{BACKGROUND OF THE STUDY}

Personality assessment has always posed huge challenges in front of researchers and psychologists. Due to its appealing nature vast population of researchers are attracted towards the exploration of this multifaceted discipline. Hence, a mammoth growth is witnessed around the world in the administration of personality assessment tests in recent years. If we explore the recent history, we will find that painstaking amendments have been made in the classical tools, with an intention to eliminate the probability of error and bias in order to keep the reliability of tools intact.

Personality is considered by most as a static entity which can be accessed through tools which are standardized and considered reliable and valid. Clearly, however, the organism is not a static entity like a stone or a piece of wood but has dynamic characteristics. Thus, as per the principles of physics, this would take a great deal of physical energy to move an object weighing, say, 120 pounds. However, the slight amount of sound energy emitted by a crying child may be quiet capable of galvanizing its mother into action. Understanding the potential of human mind is no simple aspect, which can be accessed through mere use of a standard assessment tool. Personality is dynamic, changeable, progressive; something which will require a sincere effort for its relevant understanding.

However, establishing reliability adhering to the standard procedures, at the time of tool construction or modification doesn't allege that the tool is programmed to perform consistently every time it will be employed. There are other factors as well which are to be regulated, in order to achieve testing standards which are proved to be consistent generation by generation. Reliability is a process, which if not employed meticulously each time a tool is used, will fall far short of being uniform and trustworthy; especially when we are dealing with something as complex and dynamic as human persona.

Personality assessment through questionnaires has predominantly been an integral part of research studies conducted in any educational area today. Even though no research instrument has capacity to tap into the "reality" of what an individual thinks about a particular issue still questionnaires have their own place in personality assessment.

${ }^{1}$ Research Scholar, Bangalore University, India

(C) 2015, S Aggarwal; licensee IJIP. This is an Open Access Research distributed under the terms of the Creative Commons Attribution License (http://creativecommons.org/licenses/by/2.0), which permits unrestricted use, distribution, and reproduction in any Medium, provided the original work is properly cited. 


\section{PURPOSE OF THE STUDY}

The present study intents to elucidate the existing scenario pertaining to the monotonous practices seen in administration of questionnaire based psychological testing. As more and more researchers, especially students and early career researchers are becoming content by mere harnessing of a standard tool to their respective studies. The process of test administration becomes droning and unrewarding, as an apparent disregard is noticed in the researches in recent years, for the scientifically acclaimed procedures which are time tested.

I found shocking results from one of my recent studies in which 471 college students from various Indian states ranging from 16-30 years of age $(19.90 \pm 1.77)$ were selected as sample. The subjects answered a survey slip comprising two questions in which they were asked to tick the most appropriate alternative according to their preferences.

\section{Diagram-1}

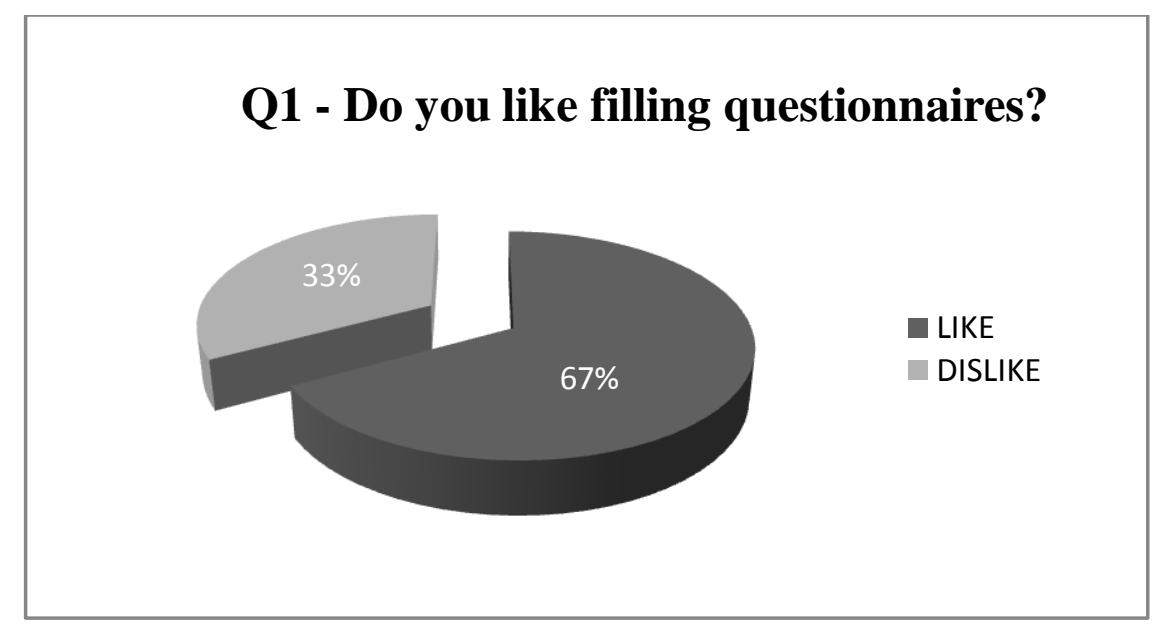

Out of 471 athletes $33 \%$ reported disliking for filling questionnaires where as $67 \%$ reported liking. One sample t-test was applied and the t-statistic was significant at the .01 critical alpha level, $\mathrm{t}(471)=7.855 \mathrm{p}=.00$ respectively. 
Diagram-2

\section{Q2 - Do you respond honestly while answering questions?}

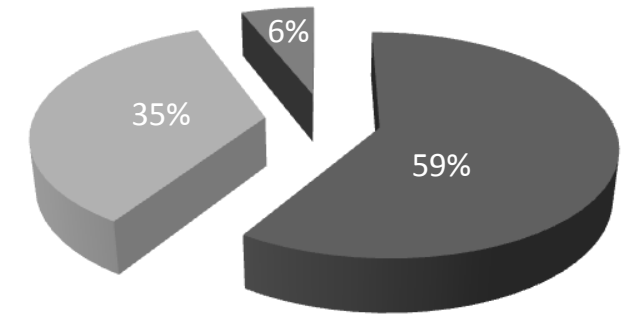

- HONEST

DISHONEST

BLUFF OCCASSIONALLY

In their response towards, honesty in filling up questionnaire, 59\% reported being honest, 35\% said that they never respond honestly and $6 \%$ proclaimed that they don't mind bluffing while choosing a response. The t-statistic was significant at the .01 critical alpha level,

$$
\mathrm{t}(471)=5.551 \mathrm{p}=.00 \text { respectively. }
$$

In this study even though the percentage of subjects who like filling questionnaires and who respond honestly is found to be significant, the percentage which reported disliking and dishonesty cannot be ignored as error of approximately $40 \%$ is clearly capable of tossing the inferences drawn up side down in any study and should not be trusted. Hence, with these results the researcher infers that there is a huge lagging in the established standards and the superficiality with which they are applied to many studies today, especially the work conducted by students and early career researchers.

\section{Reliability v/s Personality}

In Oxford English dictionary reliability or reliable is defined as "able to be dependent on or trusted, constant, faithful etc." whereas on the other hand personality is defined as "the characteristics or qualities that form a person's character or nature or disposition. Hence, reliability is something which is a constant whereas personality is something which is dynamic. In other words, we are thinking that a method, with characteristics just opposite to the variable being tested is potent for obtaining trustworthy inferences and results. We are actually trusting studies which have flaw in the understanding of reliability in context of personality assessment. How personality which is so dynamic, complex and changeable could be evaluated with a method or tool which is just opposite to its basic nature.

\section{DISCUSSION OF FINDINGS}

Researchers have always trusted inferences of the most untrustworthy, assessed nonstandard with methods which are standard, tried to evaluate things scientifically which till date 
are posing challenges to scientists, tried establishing simple and static ways of assessment in lieu of capturing something which is so complex and dynamic.

I just don't think this way, a personality assessment tool which is scientific and assures being reliable cannot possess potential to capture the dynamism of human personality. Questionnaires like MBTI, EPI, MMPI etc. all might have shown promising performance when it comes to reliability and validity quotient, but if we test them on the basis of assessing the dynamism, changeability and complexity of human nature i.e. the 'true persona' of an individual they will surely fall far short of being successful.

\section{CONCLUSION}

Psychological measurement is obviously not much like physical measurement. If we measure the height or weight of an adult with a ruler, we have no reason to suppose that a second measurement will give us a different result, provided our measurements are not varied by factors such as meal eaten or ill health, which would have a good deal of bearing on subject's weight. This is the essential problem of reliability. For psychological characters, we can expect to find a good deal more fluctuation than we do with weight. People vary greatly in their motivation, their moods, and their feelings. These factors may have a greater or lesser effect, depending on what trait the test is measuring. In case of personality the results in a test is greatly affected by these irrelevant or, error, factors and how far it represents real or true persona.

The data we gather are very complex in the sense that there are many variables than we can exactly control. Thus, psychology is not, for the most of the part, like classical physics, in which experimental findings are highly reliable and can usually be stated in exact mathematical terms. This doesn't however; make psychology any less a science. It employs basically the same general methods as physics and follows the same quest for empirical truth.

Hence, it's our responsibility as a researcher to prevent from mere talking of test administration standards and instigate their application in our work. Because such deception is only going to make the understanding of personality further more complicated and multifarious.

The way we are conducting personality studies at present for the mere sake of being scientific is going to make our journey towards exploration of truth even more daunting. Studies are referred and generalizations are made. Repeated negligence in the administration gives results which relate positively but how sure can we be that they are actually truly related or they are showing relation because they both have missed the same technicalities in administration of the test. Hence, any personality or behavioral study must be assessed based on its administration standards.

Finally the researcher appeals that the way standard questionnaires form a compulsory part of a test administration process similarly we must agree upon a standard test administration battery without whose application a personality or behavioral study shall not be considered standard, scientific and complete. 


\section{BIBLIOGRAPHY}

1. Thompson, R. T., \& DeBold R. C. (1971). Psychology: A Systematic Introduction. New York: McGraw Hill

2. Pervin, L. A. (1970). Personality: Theory, Assessment and Research. Oxford, England: John Wiley \& Sons

3. Elasy, T. A., \& Gaddy, G. (1998). Measuring subjective outcomes: Rethinking reliability and validity. Journal of General Internal Medicine, 757-761. Retrieved November 27, 2013 from: http://www.ncbi.nlm.nih.gov/pubmed/9824522 